\title{
PENERAPAN ASPEK-ASPEK ERGONOMI PADA WORKSHOP PENGELASAN DI LPKA KELAS II TOMOHON
}

\author{
I Wayan Gede Suarjana ${ }^{1^{*}}$, Moh. Fikri Pomalingo ${ }^{2}$, Bastian Rikardo Parhusip ${ }^{3}$, \\ Muh. Muhdi Ataufiq ${ }^{4}$ \\ ${ }^{1-4}$ Universitas Negeri Manado \\ Email Korespondensi: iwg.suarjana@unima.ac.id \\ Disubmit: 23 Januari 2022 Diterima: 25 Januari 2022 Diterbitkan: 01 Februari 2022 \\ DOI: https://doi.org/10.33024/mnj.v5i2.5893
}

\section{ABSTRACT: IDENTIFICATION OF ERGONOMIC ASPECTS AT WELDING WORKSHOP AT LPKA KELAS II TOMOHON}

Introduction: LPKA Kelas II Tomohon Is a Special Children's Development Institution that has the duties and functions of to build, guide and protect every student who has problems with the law. One of the coaching programs implemented is welding process training to improve the creativity of community students.

Purpose: This research aims to identify the application of eight aspects of ergonomics to welding workshop participants in LPKA Kelas II Tomohon.

Method: The design of this study is an observational analytical approach that is observation without intervention to uncover the facts of a cause and effect described descriptively. This research was conducted by observing the workings and work environments including, human interaction of machines, and the physical environment. This research is focused on the training process of welding practice. Respondents from this study amounted to 14 respondents who took welding training. The study was conducted from May 2021 to June 2021.

Result: Based on observations and measurements that are known that in working conditions in welding workshops are still not ergonomic, it can be seen from the absence of physiological work attitude arrangements when doing activities, irregular rest arrangements, lack of muscle stretching activity at rest, and the use of welding glasses and masks that have not been applied when doing the welding process.

Conclusion: Based on the identification of the application of 8 aspects of ergonomics that are still a priority of attention that are at risk of health problems in worksop participants, namely from aspects of work attitudes that are still not in accordance with physiological / ergonomic attitudes, the social condition of the participant's work culture is still lacking in the culture of the use of personal protective equipment to ensure work safety, and humanmachine interaction is still not appropriate, namely from the correct use of tools in accordance with their function, Work facilities such as desks have not met, fiber working conditions that can still pose health risks to workers that need to be a concern.

Keywords: ergonomic aspects, occupational health, welding 


\section{INTISARI : IDENTIFIKASI ASPEK-ASPEK ERGONOMI DI WORKSHOP PENGELASAN DI LPKA KELAS II TOMOHON}

Pendahuluan: LPKA Kelas II Tomohon adalah Lembaga Pembinaan Khusus Anak yang memiliki tugas dan fungsi utnuk mebina, membimbing dan mengayomi setiap anak didik permasyarakatan yang bermasalah dengan hukum. Salah satu program pembinaan yang dilaksanakan yaitu pelatihan proses pengelasan untuk meningkatkan kreatifitas anak didik permasyarakatan.

Tujuan: Penelitian ini bertujuan untuk mengidentifikasi penerapan delapan aspek ergonomi pada peserta workshop pengelasan di LPKA Kelas II Tomohon.

Metode: Rancangan pada penelitian ini adalah dengan pendekatan analitikobservasional yaitu pengamatan tanpa intervensi untuk mengungkap fakta suatu sebab-akibat yang diuraikan secara deskriptif. Penelitian ini dilakukan dengan melakukan observasi terhadap cara kerja dan lingkungan kerja meliputi, interaksi manusia mesin, dan lingkungan fisik.

Hasil: Berdasarkan Pengamatan dan Pengukuran yang dilakaukan diketahui bahwa pada program pengelasan dilihat dari penerapan aspek-aspek ergonomi yaitu Status gizi, sikap kerja, penggunaan tenaga otot, kondisi lingkungan, kondisi waktu, kondisi sosial, kondisi informasi dan kondisi interaksi manusiamesin telah diterapkan walaupun dibeberapa aspek yang masih perlu diterapkan untuk terciptanya kondisi kerja yang aman, nyaman, sehat, efisen dan efektif.

Simpulan: Berdasarkan identifikasi penerapan 8 aspek ergonomi yang masih menjadi prioritas perhatian yang berisiko terjadinya gangguan kesehatan pada peserta worksop yaitu dari aspek sikap kerja yang masih belum sesuai dengan sikap fisiologis/ergonomis, kondisi social budaya kerja peserta masih kurang dalam budaya penggunaan alat pelindung diri untuk menjamin keselamatan kerja, serta interaksi manusia-mesin masih belum sesuai yaitu dari penggunaan alat yang benar sesuai dengan fungsinya, fasilitas kerja seperti meja kerja belum memenuhi, serat kondisi kerja yang masih dapat menimbulkan risiko kesehatan pekerja yang perlu menjadi perhatian.

Kata Kunci : aspek ergonomi, kesehatan kerja, pengelasan 


\section{PENDAHULUAN}

Ergonomi merupakan komponen aktivitas yang penting dan sangat luas meliputi penyerasian alat, cara kerja, dan lingkungan kerja terhadap kemampuan, kebolehan dan keterbatasan manusia dalam upaya menciptakan kondisi kerja yang sehat, aman, nyaman, efisien dan efektif untuk tercapainya produktivitas kerja serta kesejahteraan manusia.

Dari definisi tersebut, dapat diketahui bahwa semua disiplin ilmu yang membicarakan manusia dalam beraktivitas baik saat waktu istirahat, melakukan rekreasi, olahraga, maupun pada saat beraktivitas dalam pekerjaan akan melibatkan ergonomi didalamnya (Sutjana, 2015).

Dalam aktivitas kerja baik secara manual atau umum dalam perhatian terhadap kenyamanan, kesehatan dan keselamatan kerja manusia tanpa disadari akan mempengaruhi efektifitas, efisiensi dan produktivitas kerja. Ergonomi yang secara umum diartikan 'the study of work" telah mampu membawa perubahan yang signifikan dalam mengimplementasikan konsep peningkatan produktivitas melalui efisiensi penggunaan tenaga kerja dan pembagian kerja berdasarkan spesialiskeahlian kkerja manusia (Bridger, 2003; Sanders \& McCormick, 1998).

Sebagian besar orang akan terlibat dalam proses pekerjaan baik fisik maupun mental. Kerja adalah bagian dari hidup mereka yang tidak dapat dikontrol. Dalam kata lain kerja mengacu pada semua aktivitas kehidupan manusia yang melibatkan tujuan atau usaha. Aktivitas Kerja biasanya melibatkan penggunalaan mesin dan alat-alat untuk menunjang manusia menyelesaikan pekerjaannya. Dengan meningkatnya kompleksitas mesin-mesin dan peralatan kerja yang digunakan, maka pendekatan ergonomi dalam perencanaan pekerjaan tidak sepenuhnya memadai. oleh karena itu untuk menjamin tercapainya efisiensi maksimum dari setiap oprasi, meminimalkan kemungkinan kesalahan yang dibuat oleh manusia, mengurangi kelelahan dan berupaya menghilangkan setiap risiko terhadap operator, maka diperlukan perencanaan kondisi kerja yang didasarkan pada pertimbangan anatomi, fisiologis, dan psikologis terhadap kapasitas kemampuan dan keterbatasan manusia (Susihono, 2017)(Susihono, 2017).

LPKA Kelas II Tomohon adalah Lembaga Pembinaan Khusus Anak (LPKA) yang memiliki tugas dan fungsi utnuk mebina, membimbing dan mengayomi setiap anak didik permasyarakatan yang bermasalah dengan hukum. Cara didikannya pun berbeda dengan para narapidana dewasa dimana anak didik permasyarakatan lebih mengarah pada pembinaan menyangkut dengan pembelajaran dan pembinaan kreatifitas yang dimiliki anak didik permasyarakatan.

Salah satu program pembinaan yang dilaksanakan yaitu pelatihan proses pengelasan untuk meningkatkan kreatifitas anak didik permasyarakatan, terdapat 14 anak pembinaan sebagai peserta pelatihan proses pengelasan dengan waktu kerja yaitu 5 Jam pelatihan selama 5 Hari dalam seminggunya.

Setiap pekerjaan selalu berisiko terjadinya bahaya. Demikian pula dalam proses pengelasan. Bahaya yang dihadapi dalam pengelasan meliputi tersetrum mesin las listrik, radiasi elektroda las, asap. Menurut Yusmita, dkk, secara umum bahaya pengelasan yang sering terjadi yaitu tersengat arus listrik, iritasi kulit, iritasi mata, luka 
dan cidera otot rangka, gangguan pernapasan, luka bakar, peningkatan suhu tubuh yang memicu heat stress, nyeri punggung dan bahu, kebosanan, kejenuhan serta kebisingan. Selain itu bahaya yang ditimbulkan adalah bekerja dengan alat yang tidak biasa digunakan dan bekerja dengan sikap kerja yang tidak alamiah, yang menyebabkan terjadinya gangguan fisiologis pekerja.

Tujuan utama penerapan ergonomi adalah meningkatkan produktivitas dan perlindungan kerja. Dengan kata lain, ergonomi menyangkut perencanaan kerja dan kondisi kerja yang aman bagi kesehatan pekerja baik secara fisik maupun mental. Pemahaman tentang pentingnya peran ergonomi dalam setiap aktivitas harus disadari oleh setiap pekerja dengan upaya yang sungguh-sungguh untuk berpartisipasi dalam menerapkannya sesuai dengan kondisi lingkungan.

Berdasarkan uraian diatas peneliti tertarik untuk melakukan penelitian tentang "Identifikasi aspekaspek ergonomi pada workshop pengelasan di LPKA Kelas II Tomohon". Identifikasi Aspek-aspek ergonomi yang dimaksud antara lain meliputi 8 Aspek Ergonomi; 1) Status gizi, 2) Sikap kerja, 3) Penggunaan tenaga otot (Biomekanika), 4) Kondisi lingkungan kerja, 5) Kondisi waktu, 6) Kondisi social, 7) Kondisi informasi, 8) Interaksi manusia-mesin.

\section{METODE PENELITIAN}

Rancangan pada penelitian ini adalah dengan pendekatan analitikobservasional yaitu pengamatan tanpa intervensi untuk mengungkap fakta suatu sebab-akibat yang diuraikan secara deskriptif. Penelitian ini dilakukan dengan melakukan observasi terhadap cara kerja dan lingkungan kerja meliputi interaksi antara manusia, interaksi manusia mesin, dan lingkungan fisik. Penelitian ini difokuskan pada proses pelatihan praktek pengelasan. Penelitian ini dilakukan dari bulan Mei 2021 sampai dengan Juni 2021.

Lingkungan fisik yang diukur adalah pencahayaan (lux), Kebisingan $(\mathrm{dB})$, temperatur $\left({ }^{\circ} \mathrm{C}\right)$ dan kelembaban udara (\%). Hasil pengukuran kondisi lingkungan fisikkemudian dibandingkan dengan kondisi lingkungan fisik pada peraturan Nilai Ambang Batas (NAB) berdasarkan Keputusan Menteri Kesehatan RI No. 1405/MENKES/SK/XI/2002.

Pengamatan diambil pada 5 titik pengukuran pada area kerja kemudian dihitung rerata untuk mengetahui kondisi lingkungan kerja yang dihadapi. Pengolahan data yang digunakan dengan menggunakan Microsoft Excel.

Menganalisis status gizi, penggunaan tenaga otot, kondisi waktu, dan kondisi sosial dilakukan dengan interview terhadap pekerja, sedangkan pengamatan terhadap sikap tubuh, kondisi informasi, dan interaksi manusia-mesin dilakukan dengan merekam kegiatan berupa gambar dan video agar lebih mudah diamati dan dianalisis.

\section{HASIL PENELITIAN \\ Proses Pengelasan}

Tahapan pertama adalah pemotongan pelat besi dan batang besi sesuai dengan ukuran untuk dibentuk menjadi barang yang sesuai dengan yang ditetapkan oleh instruktur pelatihan. Pemotongan dilakukan dengan menggunakan peralatan kerja yaitu gerinda potong.

Tahap selanjutnya setelah besi dan pelat dipotong sesuai dengan ukuran, lalu proses dilanjutkan dengan melakukan spot welding (pengelasan 
titik). Proses spot welding tersebut bertujuan untuk mengunci pergerakan pelat agar tidak bergeser ketika proses pengelasan dilakukan. Tahapan ini dilakukan dibawah yaitu tepat diatas lantai.

Langkah selanjutnya apabila spot welding sudah dilakukan, maka kemudian melakukan pengelasan keseluruhan. Sehingga kedua material bahan yang hendak disambung melalui proses pengelasan menjadi tersambung menjadi satu bagian utuh.

Tahapan terakhir dalam proses pengelasan ketika sudah menjadi objek berupa barang, maka tahap akhir melakukan pengasahan/penggerindaan hasil proses las disetiap sambungan las. Proses ini dilakukan dengan menggunakan gerinda dengan posisi kerja jongkok maupun berdiri.

\section{Karakteristik Responden}

Table 1. Karakteristik Responden

\begin{tabular}{lccc}
\hline Variabel & Rerata & SB & Rentangan \\
\hline Umur (Tahun) & 19.3 & 0.88 & $18-21$ \\
$\begin{array}{l}\text { Tinggi Badan } \\
\text { (cm) }\end{array}$ & 168.7 & 5.30 & $159-176$ \\
$\begin{array}{l}\text { Berat Badan } \\
\text { (kg) }\end{array}$ & 60.3 & 7.42 & $45-73$ \\
IMT (kg/m2) & 21.2 & 2.25 & $\begin{array}{c}15.66- \\
24.14\end{array}$ \\
\hline
\end{tabular}

Berdasarkan table 1 dapat dilihat bahwa karakteristik responden diketahui umur responden sejumlah 14 responden memiliki rerata 19,3 tahun dengan rentangan 18-21 tahun, tinggi badan rerata $168,7 \mathrm{~cm}$ dengan

\section{Delapan Aspek Ergonomi}

\section{1) Status Gizi}

Berdasarkan data yang didapat dari tabel 1 karakteristik responden, status gizi pekerja pada praktek proses pengelasan dapat digambarkan melalui rerata indeks massa tubuh (IMT) dalam status normal sebesar 21,2 pada rentangan 15,25-24,14.

\section{2) Sikap Kerja}

Pengamatan terhadap sikap kerja yang dilakukan oleh pekerja dalam aktivitas proses pengelasan dapat dilihat pada gambar 1 berikut. rentangan 159-176 cm, berat badan $60,3 \mathrm{~kg}$ dengan rentanagan $45-73 \mathrm{~kg}$, dan Indeks Massa Tubuh memiliki rerata 21,2 dengan rentangan 15,66-24,14 $\mathrm{kg} / \mathrm{m}^{2}$.

Berdasarkan gambar 1 dapat dilihat postur tubuh pekerja saat melakukan pengelasan dengan postur kerja yang tidak alamiah yaitu postur kerja secara paksa dengan posisi membungkuk. Aktivitas pengelasan yang dilakukan di lantai dan tanpa menggunakan meja kerja khusus, sehingga pekerja memiliki risiko sakit pada kaki dan pinggang. Melakukan pekerjaan dengan sikap kerja secara paksa akan berisiko terjadi gangguan muskuloskeletal. 


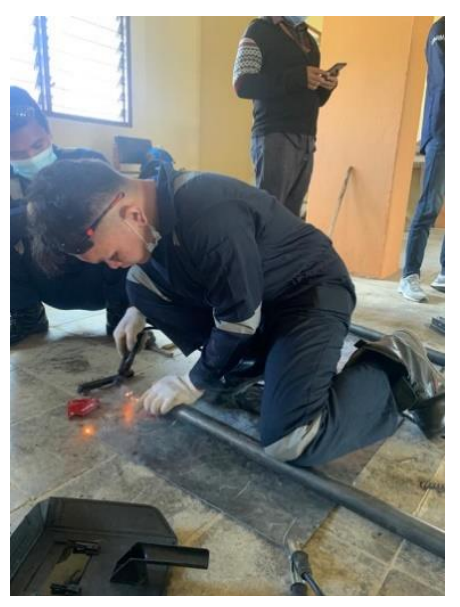

Figure 2. Sikap Kerja Proses Pengelasan

Berdasarkan gambar 2 dapat dilihat postur tubuh pekerja saat melakukan aktivitas pemotongan bahan dilakukan dengan sikap kerja yang tidak alamiah dengan posisi jongkok. Hal ini mengakibatkan terjadinya risiko gangguan muskuloskeletal, dan kaki tertekuk mengakibatkan risiko pegal pada bagian kaki dan pinggang. Aktivitas tersebut dilakukan dengan waktu yang relatif lama serta berulangulang.

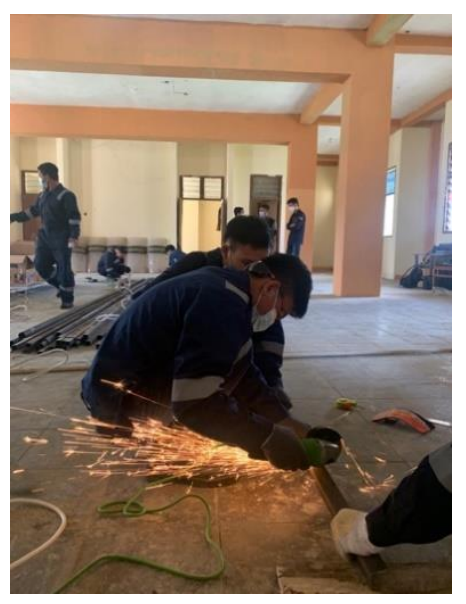

Figure 2. Sikap Kerja Proses Pemotongan Bahan

\section{3) Penggunaan Tenaga Otot \\ Penggunaaan tenaga otot pada saat melakukan beberapa aktivitas pekerjaan yang dilakukan termasuk dalam dalm kegiatan yang tidak terlalu membutuhkan penggunaan tenaga otot yang berlebihan.}

4) Kondisi Lingkungan Kerja Fisik Berdasarkan hasil pengukuran kondisi lingkungan fisik di area kerja sebagai berikut: 
Table 2. Data Kondisi Lingkungan Kerja Fisik

\begin{tabular}{|c|c|c|c|c|c|c|}
\hline \multirow{2}{*}{ Indikator } & \multicolumn{5}{|c|}{ Pengambilan pada titik } & \multirow{2}{*}{ Reratz } \\
\hline & 1 & 2 & 3 & 4 & 5 & \\
\hline $\begin{array}{l}\text { Pencahayaan } \\
\text { (lux) }\end{array}$ & 170 & 168 & 88 & 153 & 150 & 145.8 \\
\hline $\begin{array}{l}\left({ }^{\circ} \mathrm{C}\right) \\
\text { Kelembaban }\end{array}$ & 29 & 29 & 29 & 29 & 29 & 29 \\
\hline $\begin{array}{l}(\%) \\
\text { Kebisingan }\end{array}$ & 65 & 65 & 65 & 65 & 65 & 65 \\
\hline & 95.7 & 92.3 & 92.6 & 70.8 & 90.2 & 88.32 \\
\hline
\end{tabular}

Berdasarkan tabel 2 diatas, diketahui bahwa pada area kerja memiliki rerata tingkat pencahayaan

\section{5) Kondisi Waktu}

Dalam upaya pemulihan tenaga tentunya sangat dibutuhkan waktu istirahat aktif untuk melepaskan lelah dalam sesaat dan mengurangi beban kerja (Susihono, 2014). Jam kerja seperti diuraikan di atas, sudah sesuai bahkan dibawah ketentuan yang ditetapkan pemerintah, yaitu 5 jam kerja. Sedangkan untuk waktu istirahat aktif tidak diberikan.

\section{6) Kondisi Sosial}

Kondisi sosial budaya kerja dapat berupa interaksi antar rekan kerja, masyarakat keluarga, dan perusahaan. Kondisi pada program pelatihan pengelasan pada LPKA Kelas II Tomohon antara lain adalah adanya briefing antara pekerja pada pagi hari sebelum aktivitas praktek dimulai. Hal ini dilakukan upaya untuk mengingatkan pekerja terhadap kemungkinan terjadinya kecelakaan kerja, selain itu untuk mengarahkan pekerjaan apa saja yang akan dilakukan pada hari tersebut. kurangnya komunikasi komunikasi antara instruktur dan pekerja dapat mengakibatkan terjadinya kesalahan dalam meyelesaikan pekerjaan. sebesar 145,8 lux, temperatur lingkungan $29{ }^{\circ} \mathrm{C}$, kelembaban udara $65 \%$, dan kebisingan sebesar $88,32 \mathrm{~dB}$.

Sedangkan budaya lainnya seperti masih kurangnya kesadaran pekerja untuk menggunakan Alat Pelindung Diri (APD) pada saat melakukan pengelasan sehingga risiko kecelakaan kerja atau penyakit akibat kerja. Alat pelindung diri pada proses pengelasan pada umumnya yang harus digunakan meliputi; Topeng Las, sepatu safety, sarung tangan anti panas, kacamata safety, masker, apron, earplug.

\section{7) Kondisi Informasi}

Kondisi informasi pada area workshop tidak adanya pemasangan informasi upaya menghindari adanya kecelakaan kerja, informasi letak pengambilan baraang dan peletakan kembali suatu barang, maupun sebagai upaya sebagai upaya menminimalisasi kegiatan bertanya pada instruktur workshop. Kemudian tidak adanya papan informasi mengenai target kerja yang sedang dikerjakan sebagai informasi yang akan dicapai.

Tidak adanya informasi pembagian pekerjaan dan tugas pekerja pada periode tertentu, sehingga job description pekerja belum terdokumentasi secara tertulis. 
Area kerja workshop belum adanya petunjuk mengenai jalaur evakuasi jalur aman dan tidak amannya suatu area kerja. Misalkan jalur evakuasi jika terjadinya kecelakaan kerja.

\section{8) Interaksi manusia-Mesin}

Interaksi manusia-mesin dapat ditemukan pada proses penggunaan peralatan kerja saat memotong bahan

\section{PEMBAHASAN}

\section{Karakteristik Responden}

Data hasil analisis dari karakteristik responden peserta workshop dilihat dari Umur, tinggi badan, berat badan dan Indeks Massa Tubuh (IMT).

Dari hasil penelitian karakteristik umur responden dengan didapat rerata umur responden 19 Tahun dengan rentangan 18-21 Tahun. Umur merupakan salah satu faktor kondisi fisik yang dapat mempengaruhi kinerja manusia dalam melakukan aktivitas pekerjaan. Menurut Bridger, (2003) terjadinya degradasi terhadap tulang terjadi mulai pad saat usia 30 tahun siring dengan peningkatan umur sesorang. Degradasi tulang ini menyebabkan menurunnya stabilitas pada otot dan tulang sehingga semakin tua umur semakin tinggi risiko mengalami penurunan elastisitas tulang yang mengakibatkan gangguan muskuloskeletal (Kurniasih, 2009; dalam Prawira, 2017).

Umur para pekerja workshop pengelasan yang dijadikan responden berada pada umur 18 sampai dengan 21 tahun. Umur pekerja juga termasuk kategori usia produktif yang dimana umur pekerja berada antara umur 15 sampai dengan 60 tahun (International Labour Organization, 2005)

Menurut teori dari Oborne, (1995) bahwa keluhan muskoloskeletal biasanya dialami oleh sesorang pada dengan menggunakan alas kayu agar peralatan kerja tidak mengenai lantai. Pada proses pengelasan pekerja melakukan aktivitas di lantai karena tidak tersedianya meja kerja khusus, sehingga mengakibatkan pekerja melakukan aktivitas pengelasan dengan sikap kerja tidak fisiologis dengan waktu yang relatif lama.

usia kerja yaitu 24-65 tahun dan keluhan pertama biasanya dialami pada saat usia 35 tahun dan keluhan akan meningkat seiring bertambahnya usia.

Selain itu tinggi badan dan berat badan merupakan faktor yang dapat menyebabkan terjadinya keluhan otot skeletal. (Kurniasih, 2009) menyatakan bahwa sesorang dengan ukuran tubuh pendek berasosiasi dengan keluhan pada leher dan bahu.

Dalam proses pengelasan, pekerja dapat berisiko terjadinya keluhan otot skeletal dikarenakan pekerja tidak menggunakan meja kerja khusus yang sesuai dengan antropometri pekerja, sehingga menyebabkan ketidak sesuaian stasiun kerja dengan pekerja yang memicu terjadinya sikap kerja yang tidak alamiah. Rerata tinggi badan pekerja $168,7 \mathrm{~cm}$ dan berat badan sebesar $60,3 \mathrm{~kg}$.

Dari data tinggi badan dan berat badan dibandingkan untuk mengetahui rerata Indeks Massa Tubuh pekerja pengelasan didapatkan sebesar 21,2 $\mathrm{kg} / \mathrm{m}^{2}$. Indeks massa tubuh (IMT) adalah sebuah pendekatan yang tergolong praktis dan sederhana untuk menilai status gizi seseorang (Tandirerung, Male, \& Mutiarasari, 2019). Indeks massa tubuh diklasifikasikan antara lain: underweight, normal, overweight dan obesitas. Rerata indeks massa tubuh pekerja workshop pengelasan 
dapat dikatakan masuk dalam kategori normal.

\section{Delapan Aspek Ergonomi}

\section{1) Status Gizi}

Status gizi merupakan keadaan tubuh sebagai akibat dari konsumsi makana dan penggunaan zat gizi. Status gizi yang tidak normal akan menandakan kondisi tubuh yang kurang baik. Kondisi tubuh tersebut akan mempengaruhi pekerja dalam beraktivitas dan dapat menyebabkan kelelahan kerja (Hanifah, Alwi, \& Patimah, 2021).

Hasil penelitian menunjukkan bahwa status gizi pekerja yang dilihat dari rerata indeks massa tubuh 14 pekerja tergolong dalam kategori normal yaitu $21,2 \mathrm{~kg} / \mathrm{m}^{2}$, yang menandakan bahwa status gizi pekerja dalam keadaan baik. Sesorang dengan Indeks massa tubuh yang kurang baik atau tidak normal mudah mengalami kelelahan dibandingkan dengan yang tergolong normal. Berat badan yang kurang cepat lelah dikarenakan kurangnya asupan atau energi dalam tubuh yang menunjang pergerakan tubuh dan berat badan berlebihan akan mencari waktu istirahat lebig banyak dari seseorang yang memiliki indeks massa tubuhnya normal (Hanifah et al., 2021).

\section{2) Sikap Kerja}

Sikap kerja dipengaruhi oleh karena kondisi stasiun kerja yang kurang baik. Seluruh pekerja melakukan pekerjaan pada stasiun kerja yang tidak ergonomis. Pada gambar 1 dapat dilihat proses pengelasan dilakukan diatas lantai tanpa menggunakan meja khusus. Pada gambar 2 menunjukkan proses pengasahan juga yang dilakukan dengan keaadan stasiun kerja yang tidak ergonomis.
Hasil pengamatan pada observasi pada pekerja workshop pengelasan hampir seluruh pekerja melakukan pekerjaanya dengan sikap kerja paksa atau tidak alamiah.

Nyeri punggung bagian belakang sering disebut keluhan muskoloskeletal yang merupakan gangguan otot rangka yang paling berisiko terjadinya keluhan sakit, nyeri, kaku dan pegal-pegal. Jika sikap kerja yang dilakukan terus menerus dalam jangka waktu yang lama, kemungkinan terjadinya risiko gangguan muskuloskeletal akan semakin parah.

Jika stasiun kerja tidak ergonomis maka dapat menyebabkan posisi kerja juga menjadi berisiko mengalami gangguan muskuloskeletal (Permatasari \& Widajati, 2018). Penelitian yang dilakukan oleh Larono et al. (2017) dalam Permatasari \& Widajati, (2018) menemukan hasil penelitian bahwa sikap kerja memiliki hubungan dengan keluhan muskuloskeletal yang signifikan.

3) Penggunaan Otot/Biomekanika

Biomekanika atau sering disebut dengan penggunaan tenaga otot merupakan kombinasi antara keilmuan mekanika, antropometri dan ilmu dasar kedokteran (biologi dan fisiologi), (Mas'idah, Fatmawati, \& Ajibta, 2009). dalam aktivitas pekerjaan, kekuatan kerja otot yang tergantung pada posisi anggota tubuh yang bekerja, arah gerakan dan perbedaan kekuatan antara bagian tubuh. Selain itu kecepatan dan ketelitian serta daya tahan jaringan tubuh terhadap beban material yang dapat mempengaruhi biomekanika tubuh pekerja.

Dari hasi pengamatan melalui observasi lapangan yang dilakukan dilihat tidak ada pengerahan tenaga otot yang berlebihan dalam proses 
pengelasan. Dalam proses pengelasan yang dilakukan tidak terdapat beban material yang perlu diangkat dengan menggerahkan sebagian besar tenaga otot pekerja.

Menurut Mas'idah et al., (2009) mengklasifikasikan batas pembebanan angkat angkut material berdasarkan umur antara lain: pria dibawah umur 16 tahun maksimum angkat adalah $14 \mathrm{~kg}$, pria umur 16-18 tahun maksimum angkat adalah $18 \mathrm{~kg}$, pria umur lebih dari 18 tahun tidak ada batasan angkat, wanita umur 16-18 tahun maksimum angkat adalah $11 \mathrm{~kg}$, sedangkan wanita umur lebih dari 18 tahun maksimum angkat yang diperbolehkan adalah 16 $\mathrm{kg}$.

Batasan-batasan angkat tersebut dapat membantu mengurangi risiko terjadinya low back pain diantaranya mengurangi rasa nyeri, ngilu dan patah. Dengan batasan-batasan ini dapat mengurangi ketidaknyamanan dalam bekerja yang berhubungan dengan material manual handling.

Manusia selain menggunakan alat sebagai salah satu cara dalam menyelesaiakan suatu pekerjaannya, ada faktor lain yang mempengaruhi produktivitas kerja manusia dalam pekerjaannya, yaitu faktor lingkungan, (Putra, 2017).

\section{4) Kondisi Lingkungan Kerja}

Pengukuran pada kondisi lingkungan fisik pada ruang kerja workshop pengelasan didapatkan rerata intensitas pencahayaan 145,8 lux. Pencahayaan pada ruag kerja ini yang digunakan ialah pencahayaan alami dan pencahayaan buatan. Tetapi, pencahyaan buatan berupa lampu fluorescent (NEON) yang menyala hanya satu titik dibagian tengah ruangan yang besarnya 8 watt. Tingkat pencahayaan ruangan kerja dari pencahyaan alami yaitu sinar matahari yang masuk melalui ventilasi di bagian sisi kanan dan kiri ruangan yang cukup memadai untuk pencahyaan dalam melakukan pekerjaan. Sesuai dengan Ketentuan Persyaratan Kesehatan Lingkungan Kerja Perkantoran dan Industri, yaitu pengelasan termasuk dalam kategori pekerjaan kasar dan tidak terus menerus dengan keterangan pekerjaan dengan mesin dan perakitan kasar memiliki tingkat pencahayaan minimum sebesar 300 lux. Jika dilihat dari hasil pengukuran yang didapatkan jauh dari persyaratan yang ditentukan pemerintah.

Kebutuhan pencahayaan yang optimal sangat diperlukan. Tingkat pencahayaan yang baik merupakan salah satu faktor untuk memberikan kondisi pengelihatan yang baik. Dengan tingkat pencahayaan yang baik akan memudahkan gabi pekerja dalam melihat dan mengurangi kesalahan dalam melakukan pekerjaan.

Kemampuan mata melihat objek dipengaruhi oleh ukuran objek, derajat kontras antara objek dan sekelilingnya, brightness, lamanya melikat, serta warna dan texture yang memberikan efek psikologis pada manusia.

Data pengukuran temperatur ruang kerja yang didapat pada tabel 2 menunjukkan nilai temperatur sebesar $29{ }^{\circ} \mathrm{C}$ dengan kelembaban relatif sebesar $65 \%$. Dari hasil data temperatur dan kelembaban yang diperoleh dapat dikatakan ruang dalam keadaan kondisi nyaman.

Kelembaban sangat berhubungan dengan temperatur udara, semakin rendah suhu, akan semakin meninggakatnya nilai kelembaban begitu juga sebaliknya. Pengaruh yang disebabkan oleh kelembaban dan temperatur yang tidak ergonomis dapat menyebabkan pengurangan panas dalam tubuh secara besar-besaran, disamping itu juga dapat menyebabkan 
semakin cepatnya denyut jantung karena makin aktifnya peredaran darah untuk memenuhi konsumsi oksigen. Hal ini dapat menyebabkan timpulnya risiko kelelahan dalam bekerja. Sesuai dengan Keputusan Menteri Kesehatan Nomor: $\quad$ 1405/Menkes/SK/XI/2002, tentang Nilai Ambang Batas Lingkungan Kerja untuk temperatur ruangan sebesar $18-30^{\circ}$ dengan kelembaban relatif antara $65-90 \%$.

Kebisingan dapat diartikan sebagai bunyi-bunyian yang tidak dikehendaki. kebisingan dengan intensitas yang melebihi batas normal yang berasal dari kegiatan usaha dalam tingkat dan waktu tertentu dapat menyebabkan gangguan berkomunikasi, gangguan kesehatan, dan berdampak pada kenyamanan (Mukhlish, Sudarmanto, \& Hasan, 2018).

Hasil pengukuran yang dilakukan terlihat pada tabel 2 di atas, rerata $88,32 \mathrm{~dB}(\mathrm{~A})$. Kebisingan bersumber dari mesin gerinda yang digunakan dalam proses pemotongan bahan pengelasan. Mesin gerinda yang digunakan secara bersamaan berjumlah 2 alat gerinda yang aktif secara bersamaan, serta sumber kebisingan lainnya ditimbulkan melalui penempaan bahan berupa besi menggunakan hammer.

Kebisingan yang ditimbulakan pada tempat kerja sangat berpengaruh terhadap peningkatan tekanan darah dan denyut nadi manusia. Saraf simpatis yang mendapat stimulasi akan mempengaruhi pembuluh darah arteri radialis dan vena sehingga menyebabkan vasokontraksi. Jika hal tersebut terjadi dalam jangka waktu hingga lima tahun, maka dapat menyebabkan hipertensi dan memiliki $60 \%$ lebih tinggi risiko kematian akibat penyakit kardiovaskular dalam kurun waktu lebih dari 10 tahun, dibandingkan dengan pekerja yang tidak pernah terpapar kebisingan (Zeeb et al., 2017).

Dalam Peraturan Menteri Tenaga Kerja dan Transmigrasi No. PER/13/MEN/X/2011 tentang nilai ambang batas kebisingan sebesar 85 $\mathrm{dB}(\mathrm{A})$. Nilai tersebut jika dibandingkan dengan hasil observasi lapangan yang dilakukan sebesar 88,32 $\mathrm{dB}(\mathrm{A})$ masih dapat diterima oleh pekerja tanpa mengakibatkan penyakit atau gangguan kesehatan dalam pekerjaan untuk waktu yang tidak sampai dengan 8 jam sehari atau 50 jam seminggu.

\section{5) Kondisi Waktu}

Lama waktu dalam bekerja dalam sehari yang telah ditetapkan pada umumnya 6-8 jam kerja. Jumlah waktu yang efisien untuk seminggu adalah antara 40-48 jam yang terbagi dalam 5 atau 6 hari kerja dan maksimum waktu kerja tambahan yang masih efisien adalah 30 menit. Selain itu perlu diatur juga waktu-waktu istirahat khusus agar kemampuan kerja, kesegaran jasmani dapat pulih kembali atau dipertahankan.

Dari hasil pengamatan yang dilakukan terhadap lama kerja dalam pengelasan masih dalam waktu efisien yaitu 5 jam kerja dalam sehari.

Tarwaka, Solikhul, \& Sudiajeng, (2004) menyatakan semakin berat beban kerja atau semakin lama waktu kerja seseorang maka akan timbul kelelahan kerja. Beban kerja berlebih dapat menimbulkan kelelahan otot yang ditandai dengan gejala tremor atau rasa nyeri yang terdapat pada otot. Kelelahan dapat dikurangi dengan berbagai cara, dengan pengelolaan waktu bekerja dan lingkungan tempat kerja. Banyak hal yang dapat diterapkan dalam menerapkan waktu kerja dan waktu istirahat sesuai dengan ketentuan yang berlaku. 


\section{6) Kondisi Sosial Budaya Kerja}

Alat Pelindung Diri (APD) merupakan suatu alat yang mempunyai kemampuan untuk melindungi seseorang yang fungsinya untuk mengeliminasi kemungkinan selutuh anggota tubuh manusia dari potensi bahaya.

Dari hasil pengamatan dan wawancara pekerja pengelasan, sebanyak $87 \%$ yang tidak terbiasa menggunakan APD dikarenakan pekerja mengaku lebih nyaman menggenggam atau menggerakkan tubuh saat melakukan pekerjaan.

Dengan mengabaikan penggunaan APD akan memberikan risiko kecelakaan kerja yang kecelakaan kerja. Dengan penggunaan APD yang bertujuan untuk melindungi para pekerja dari kecelakaan kerja sehingga tidak mengenai pekerja secara langsung yang dapat menimbulkan cidera pada pekerja. Berdasarkan hasil penelitian yang dilakukan oleh (Listautin, 2017) menyatakan bahwa terdapat hubungan yang bermakna antara penggunaan APD terhadap kecelakaan kerja pada tenaga kerja bongkar PT. Jambi Waras sebesar 18 Responden (46,2\%) tidak menggunakan APD dan 21 responden $(53,8 \%)$ pernah mengalami kecelakaan kerja.

\section{7) Kondisi Informasi}

Sebelum dimulai kegiatan pengelasan, saat pagi hari intruktur melakukan briefing terhadap seluruh pekerja. Dengan tujuan untuk menjelasakan job description dan mengingatkan untuk pentingnya kesehatan dan keselamatan kerja yang perlu diperhatikan dalam pengelasan. Instruktur sebaiknya memberikan perkenalan keselamatan.

Penyampaian rincian tugas, prosedur dan tata tertib kerja kepada pekerja secara jelas dan terperinci dapat menekan timbulnya kesalahan kerja.

Dari hasil pengamatan terkait dengan kondisi informasi yang diterapkan antara lain: breifing, penyamaian rincian tugas, prosedur, tata tertib, dan target capaian kerja yang sudah dilakukan. Sedangkan untuk iformasi tertulis masih kurang.

Dalam penyampaian informasi, ada beberapa sistem yang dapat digunakan, antara lain dengan komunikasi lisan, informasi tertulis baik secara langsung maupun tidak langsung, dipasang papan pengumuman atau berupa sloganslogan kerja yang dipasang ditempat kerja setiap saat, dan dalam bentuk buku acuan kerja (Manuaba, 2000). Penggunaan media informasi yang tepat dengan menggunakan ukuran, warna dan penempatan yang proporsional dapat memperlancar proses produksi dan peningkatan produktivitas kerja.

\section{8) Interaksi Manusia-Mesin}

Keserasian interaksi manusiamesin. Dalam hal ini penggunaan alat kerja yang disesuaikan dengan unsur anatomi, psikologi, lingkungan dan kesehatan kerja.

Menurut Pheasant, (1988) ada tiga informasi penting yang diperlukan untuk dapat memilih ukuran terbaik yang menciptakan keserasian antara pekerja dengan mesin, yaitu karakteristik ukuran tubuh dari populasi pengguna.

Dari hasil pengamatan yang ditemukan mengenai aspek interaksi manusi-mesin masih yang ditemukan, seperti tidak tersedianya meja kerja khusus saat melakukan pengelasan, sehingga mengharuskan pekerja melakukan pengelasan dengan posisi jongkok.

Ketidaksesuaian kondisi kerja dalam aspek interaksi manusia-mesin yang tidak harmonis juga dapat 
menyebabkan kurangnya pemahaman pekerja terhadap sikap kerja yang sehata dan aman. Kondisi interaksi manusia mesin yang kurang harmonis ini menyebabkan timbulnya sikap kerja paksa, keluhan muskuloskeletal yang dilakaukan secara berulang-ulang menyebabkan terjadinya kelelahan dini (Grandjean, 1993; Pulat, 1992; Sanders \& McCormick, 1998). Oleh karena itu perlu dilakukannya langkah perbaikan di antaranya dengan melakukan design meja kerja khusus yang sesuai dengan ukuran tubuh pekerja yangdapat meminimalisasi sikap kerja yang tidak alamiah.

Pengaruh interaksi manusia-mesin terhadap gangguan sistem muskuloskeletal menurut (Grandjean, 1993), secara garis besar keluhan otot dikelompokkan menjadi dua, yaitu keluhan sementara, keluhan otot yang terjadi pada saat otot menerima beban statis, keluhan tersebut akan segera hilang apabila pemberian pemebebanan dihentikan, dan keluhan menetap yaitu keluhan otot yang bersifat tetap. Walaupun pemberian pembebanan dihentikan.

Pengaruh interaksi manusia-mesin terhadap kelelahan. Kelelahan bagi setiap orang bersifat subjektif karena terkait dengan perasaan. Hasil penelitian para ahli menyatakan bahwa keadaan dan perasaan lelah adalah reaksi fungsional dari pusat kesadaran yaitu kortex kerebri, yang dipengaruhi oleh dua sistem antagonis yaitu sistem penghambat (inhibisi) dan sistem gerak (aktivasi) (Sudiajeng, Oesman, \& Sutopo, n.d.).

\section{KESIMPULAN}

Secara umum dapat disimpulkan bahwa aspek-aspek ergonomi sebagaian besar sudah diterapkan sesuai dengan uraian diatas. Dan Kesimpulannya, sebagai berikut:
1) Karakteristik reponden yang dilihat dari umur didapat 18-21 tahun masih berada pada usia produktif.

2) Status Gizi responden yang dilihat dari Indeks Massa Tubuh (IMT) tergolong kategori normal yang sebesar $21,2 \mathrm{~kg} / \mathrm{m}^{2}$

3) Sikap kerja responden masih dalam keadaan tidak ergonomis dilihat dari postur tubuh membungkuk dan terjadi sikap paksa yang menimbulkan terjadinya risiko keluhan muskuloskeletal yang dirasakan.

4) Pengunaan tenaga otot atau biomekanika responden dari hasil observasi masih dalam batas ringan, karena material yang diangkat maupun pekerjaan yang memerlukan pengerahan tenaga otot masih minimal.

5) Kondisi lingkungan kerja yang dihadapi oleh responden, dilihat dari tingkat pencahayaan yang didapat sebesar 145,8 Lux belum memenuhi syarat yang dibutuhkan dalam proses pekerjaan pengelasan. Temperatur ruangan masih dalam kategori kondisi nyaman $29^{\circ} \mathrm{C}$. Tingkat Kebisingan $88,31 \mathrm{~dB}$ masih dapat diterima dan memenuhi syarat.

6) Kondisi waktu, dalam workshop pengelasan waktu kerja yaitu 5 jam kerja masih dalam waktu efisien.

7) Kondisi Sosial budaya kerja, dari penggunaan APD masih banyak yang tidak terbiasa dengan budaya penggunaan apd sebesar $87 \%$ responden.

8) Interaksi Manusi-Mesin, masih belum tersedianya fasilitas kerja, stasiun kerja, dan kondisi kerja yang ergonomis. 


\section{SARAN}

Untuk penelitian selanjutnya perlu dilakukan penelitian yang dapat memberikan intervensi perbaikan sesuai dengan kondisi kerja ergonomi dan stasiun kerja ergonomi yang dihadapi oleh peserta workshop agar fasilitas, stasiun kerja, dan kondisi kerja ergonomi agar pekerja dapat bekerja secara efisien, nyaman, aman, sehat dan efektif serta mencegah tejadinya penyakit akibat kerja, gangguan sistem muskuloskeletal, serta dapat meningkatkan produktivitas kerja setinggi-tingginya

\section{UCAPAN TERIMA KASIH}

Tim mengucapkan Terima Kasih kepada Kementerian Pendidikan, Kebudayaan, Riset dan Teknologi yang telah mendanai seluruh program ini. Program ini merupakan Program Kemitraan Masyarakat dari skim Pengabdian Kepada Masyarakat SIMLITABMAS Tahun 2021 dan Terima Kasih juga kepada Kepala LPKA Kelas 2 Tomohon yang senantiasa memberikan izin dan kepercayaannya terhadap tim dalam keterlaksanaan serta kerjasamanya dalam kegiatan ini, dan di dalam pelaksanaan PKM ini juga dilakukan pengambilan data untuk dilakukannya penelitian-penelitian.

\section{DAFTAR PUSTAKA}

Bridger, R. S. (2003). Introduction to Ergonomics. UK: Taylor \& Francis.

Grandjean, E. (1993). Fitting the Task to The Man (4th ed.). London: Taylor \& Francis Inc.

Hanifah, N. M., Alwi, M. K., \& Patimah, S. (2021). Hubungan Status Gizi dan Aspek Ergonomi Dengan Kejadian Low Back Pain Pada Pekerja di PT. Varia Usaha Beton. Window of Public Health Journal, 1(6), 672-683.
International Labour Organization. (2005). Access to treatment in the private-sector workplace: The provision of antiretroviral therapy by three companies in South Africa. Switzerland: World Health Organization.

Kurniasih. (2009). Tinjauan Faktor Risiko Dan Keluhan Subjektif Terhadap Timbulnya Muskuloskeletal Disorders Pada Pengemudi Travel $X$ Trans Tujuan Jakarta-Bandung Tahun 2009. Fakultas Kesehatan Masyarakat Universitas Indonesia, Jakarta.

Listautin. (2017). Hubungan Penggunaan Alat Pelindung Diri (APD), Aktivitas Kerja Berulang dan Ergonomi Terhadap Kecelakaan Kerja Pada Tenaga Kerja Bongkar PT. Jambi Waras Tahun 2016. STIKes Prima Jambi, 6(2), 86-92.

Manuaba, A. (2000). Ergonomi, Kesehatan dan Keselamatan Kerja. Proceeding Seminar Nasional Ergonomi 2000, 1-4. Surabaya: Guna Wijaya.

Mas'idah, E., Fatmawati, W., \& Ajibta, L. (2009). Analisa Manual Material Handling (MMH) dengan Menggunakan Metode Biomekanika Untuk Mengidentifikasi Resiko Cidera Tulang Belakang (Muskuloskeletal Disorders) (Studi Kasus pada Buruh Pengangkat Beras di Pasar Jebor Demak). Majalah Ilmiah Sultan Agung, 45(119), 37-56.

Mukhlish, W. I. N., Sudarmanto, Y., \& Hasan, M. (2018). Pengaruh Kebisingan Terhadap Tekanan Darah dan Nadi pada Pekerja Pabrik Kayu PT. Muroco Jember. Jurnal Kesehatan Lingkungan Indonesia, 17(2), 112-118. 
Oborne, D. (1995). Ergonomics and Human Factors (Vol. 2). UK: Edward Elgar.

Permatasari, F. L., \& Widajati, N. (2018). Hubungan Sikap Kerja Terhadap Keluhan Muskuloskeletal Pada Pekerja Home Industry di Surabaya. Journal International Occupational Safety and Health, 7(2), 220-239.

Pheasant, S. (1988). Bodyspace Anthropometry, Ergonomics and Design. London - New York Philadelphia: Taylor \& Francis.

Prawira, M. (2017). Faktor yang Berhubungan Terhadap Keluhan Muskuloskeletal Pada Mahasiswa Universitas Udayana Tahun 2016. Journal of Industrial Hygienie and Occupational Health, 1(2), 101-118.

Pulat, B. M. (1992). Fundamentals of Industrial Ergonomics (2nd ed.). New Yersey: Prentice Hall, Englewood Cliffs.

Putra, B. I. (2017). Analisa Lingkungan Kerja Fisik Pada Mahasiswa Teknik Industri Umsida. 8-14. Surabaya: Universitas Pembangunan Nasional.

Sanders, M. S., \& McCormick, E. J. (1998). Human Factor in Engineering and Design. New York: McGrawHill Book Company.

Suarjana, I., (2020) 'Analisis Beban Kerja Mahasiswa Praktikum Parasitologi Di Program Studi Ilmu Kesehatan Masyarakat Universitas Negeri Manado', Jurnal Ergonomi Indonesia, 6(1).

Sudiajeng, L., Oesman, T. I., \& Sutopo, N. (n.d.). Analisa Ergonomi Terhadap Kondisi Interaksi Manusia-Mesin Melalui Pendekatan Partisipatori Pada
Bengkel Kayu Jurusan Teknik Sipil Politeknik Negeri Bali (PNB). Jurnal Teknologi Technoscientia, 3(2), 20132220.

Susihono, W. (2014). Ergonomics Approach Analysis Sebagai Dasar Identifikasi dan Perbaikan Kondisi Kerja pada Industri Pengecoran Logam Sistem Dapur Induksi; Studi Kasus di PT. X Ceper Klaten. Proceeding Seminar Nasional, 284-290. Surakarta: Jurusan Teknik Industri Universitas Sebelas Maret.

Susihono, W. (2017). Identifikasi 8 Aspek Ergonomi di Industri Konstruksi dan Service Mesin. Jurnal Industrial Services, 2(2), 181-186.

Sutjana, I. D. P. (2015). Aspek Ergonomi Dari Risiko Psikososial di Tempat Kerja. Jurnal Ergonomi Indonesia, 1-9.

Tandirerung, F. J., Male, H. D. C., \& Mutiarasari, D. (2019). Hubungan Indeks Massa Tubuh Terhadap Gangguan Muskuloskeletal Pada Pasien Pralansia dan Lansia di Puskesmas Mamonji Palu. Jurnal Kesehatan Tadulako, 5(2), 9-17.

Tarwaka, Solikhul, H. A., \& Sudiajeng, L. (2004). Ergonomi untuk Keselamatan, Kesehatan dan Produktivitas. Surakarta: UNIBA Press.

Zeeb, H., Hegewald, J., Schubert, M., Wagner, M., Dröge, P., Swart, E., \& Seidler, A. (2017). Traffict Noise and Hypertension - Result From A Large Case-Control Study. Environment Research, 157(1), 110-117. https://doi.org/10.1016/j.envr es.2017.05.019 
TAHUN [MANUJU: MALAHAYATI NURSING JOURNAL, ISSN CETAK: 2655-2728

2022 ISSN ONLINE: 2655-4712, VOLUME 4 NOMOR 2 FEBRUARI 2022] HAL 308-322 
TAHUN [MANUJU: MALAHAYATI NURSING JOURNAL, ISSN CETAK: 2655-2728

2022 ISSN ONLINE: 2655-4712, VOLUME 4 NOMOR 2 FEBRUARI 2022] HAL 308-322 
TAHUN [MANUJU: MALAHAYATI NURSING JOURNAL, ISSN CETAK: 2655-2728

2022 ISSN ONLINE: 2655-4712, VOLUME 4 NOMOR 2 FEBRUARI 2022] HAL 308-322 